genic chemical groups free to mediate various allergic responses.

An alternative explanation may be that the inheritance of an atopic predisposition is genetically linked to the inheritance of poor metaboliser genes. Further studies on atopic patients who have no symptoms of food intolerance are in progress. It is also conceivable that sulphoxidation ability, though largely determined genetically, may be altered by certain environmental influences such as viral infections. Further studies to investigate this are being undertaken.

1 Metcalfe DD. Food hypersensitivity. I Allergv Clin Immunol 1984;73:749-58.

2 Golbert TM, Patterson R, Pruzansky JJ. Systemic allergic reactions to ingested antigens. Fournul of Allergv 1969;44:96-102.

3 Brostoff J, Carini C, Wraith DG. Food allergy: an immune complex disorder. $\mathrm{n}$ : Bostrom $\mathrm{H}$, Ljungstedt $\mathrm{N}$, eds. Theoretical and clinical aspects of allergic diseases. Stockholm, Almqvist and Wiksell, 1983:104-22.

4 Brostoff J. Mechanisms of hypersensitivity. In: Brostoff J, Challacombe SJ, eds. Food allergy and intolerance. London: Baillière, Tindall, 1987:433-55.
5 Scadding GK, Brostoff J. Immune complexes in food induced arthralgia. In Reed CE, ed. Proceedings of XII intermational congress of allergy and clinical immunology. St Louis, Missouri: C V Mosby and Co, 1986:45-50.

6 Carini C, Brostoff J. Immune complexes following food challenge. Ann Allergy 1987;59:110-7.

7 Mitchell SC, Waring RH, Haley CS, Idle JR, Smith RL. Genetic aspects of the polymodally distributed sulphoxidation of S-carboxymethyl-L-cysteine in man. Br 7 Clin Pharmacol 1984;18:507-21.

8 Evans DAP, Mahgoub A, Sloan TP, Idle JR, Smith RL. A family and population study of the genetic polymorphism of debrisoquine oxidation in man in a British population. $\mathcal{F}$ Med Genet 1980;17:102-5

9 Eichelbaum M. Defective oxidation of drugs: pharmacokinetic and therapeutic implications. Clin Pharmacokinet 1982;7:1-22.

10 Dollery CT, Fraser HS, Mucklow JC, Bulpitt CK. Contribution of environmental factors to variability in human drug metabolism. Drug Metab Rev 1979;9:297-320

11 Waring RH, Mitchell SC, O'Gorman J, Fraser M. Cytosolic sulphoxidation of S-carboxymethyl-L-cysteine in mammals and rodents. Biochem Pharmacol 1986;35:2999-3002

12 Boobis AR, Murray S, Khan GC, Robertz GM, Davies DS. Substrate specificity of the form of cytochrome P-450 catalyzing the 4-hydroxylation of debrisoquine in man. Br f Clin Pharmacol 1983;23:474-81.

13 Devonshire HW, Kong I, Cooper M, Sloan TP, Idle JR, Smith RL. The contribution of genetically determined oxidation status to inter-individual variation in phenocetin disposition. Br f Clin Pharmacol 1983;16:157-66.

Accepted 2 March 1988

\title{
Obstetric importance, diagnosis, and management of fetal tachycardias
}

\author{
Darryl J Maxwell, Diane C Crawford, Paul V M Curry, Michael J Tynan, Lindsey D Allan
}

\begin{abstract}
During 1980-7, 23 pregnancies of 22-38 weeks' duration were investigated for fetal tachycardia. Twelve were cases of supraventricular tachycardia, eight of atrial flutter, and three cases in which the rhythm varied between supraventricular tachycardia and atrial flutter. In 11 cases the fetus had developed non-immune fetal hydrops before referral; 12 cases were non-hydropic at referral but one of this group of fetuses became hydropic during treatment. No relation was found between the rate or type of arrhythmia and the presence or absence of intrauterine heart failure.
\end{abstract}

One non-hydropic infant was delivered electively prematurely. Maternal antiarrhythmic treatment was instituted in the remaining 22 cases. Conversion of the arrhythmia was achieved with digoxin alone in five cases and with a combination of digoxin and verapamil in nine. Control of the arrhythmia was achieved in seven of the 10 non-hydropic fetuses, and all were delivered at term with no deaths. Of the 12 hydropic fetuses, control was achieved in seven. Only three of the hydropic fetuses were delivered close to term. There were two deaths, both in the hydropic group. Of the whole group, five neonates suffered severe complications of prematurity.

In this series the main benefit of treatment appeared to be in prolonging gestation of those hydropic fetuses in which conversion was achieved.

Departments of Perinatal, Paediatric, and Adult Cardiology, Guy's Hospital, London Darryl J Maxwell, MRCOG, research fellow

Diane C Crawford, MSC, lecturer

Paul V M Curry, MD, consultant cardiologist Michael J Tynan, MD professor

Lindsey D Allan, MD, senior lecturer

Correspondence to: Dr L D Allan, 15th Floor, Guy's Tower, Guy's Hospital, London SE1 9RT. features.

Echocardiography successfully distinguishes atrial tachycardias from physiological sinus tachycardias in prenatal life. ${ }^{3.5}$ The best form of antenatal management and most practicable drug or drugs for the treatment of atrial tachycardia, however, are still a matter of controversy. ${ }^{6-8}$ Because this condition is uncommon most centres have only a limited number of cases on which to base conclusions on management. We present our accumulated experience with this difficult problem.

\section{Patients and methods}

Over seven years in a specialised centre for fetal echocardiography 23 fetuses were found to have atrial tachycardias. The fetal heart was examined for structural anomaly. ${ }^{9}$ The arrhythmia was identified by $M$ mode echocardiographic analysis of the relation between atrial and ventricular contraction. ${ }^{34}$ The presence and extent of pleural, pericardial, and peritoneal effusions were noted as evidence of cardiac failure. Because the evaluation of skin oedema was considered to be subjective the diagnosis of hydrops was not made on that basis. The presence of associated hydramnios was recorded. Seven fetuses were examined with an Advanced Technology Laboratories mark 3 sector scanner. In the remaining 16 cases, which presented after early 1985; the fetuses were examined with a Hewlett-Packard $77020 \mathrm{~A}$ phased array scanner.

Antiarrhythmic treatment was given to the mother in 22 cases. Treatment was aimed at restoring sinus rhythm, preventing or reversing cardiac failure, and averting preterm delivery. Digoxin alone or a combination of digoxin and verapamil was used in each case. Mothers were treated with $0.75 \mathrm{mg}$ digoxin daily and the dose adjusted to maintain the maternal serum concentration at $2.6 \mathrm{nmol} / \mathrm{l}$. Verapamil was added in increasing doses to a maximum of $480 \mathrm{mg}$ daily until control was achieved or delivery supervened. Maternal serum concentrations of digoxin and verapamil were measured at regular intervals. Standard and 24 hour electrocardiograms were recorded in mothers taking verapamil. When possible cord blood was sampled at delivery in order to assess the transplacental passage of these drugs.

\section{Results}

Table I summarises the clinical details and outcome of treatment of the fetuses that were not in heart failure 


\begin{tabular}{|c|c|c|c|c|c|c|c|}
\hline $\begin{array}{l}\text { Case } \\
\mathrm{No}^{\star}\end{array}$ & $\begin{array}{l}\text { Reason for } \\
\text { referral }\end{array}$ & $\begin{array}{c}\text { Gestation at } \\
\text { referral (weeks) } \dagger\end{array}$ & Rhythm & Treatment & $\begin{array}{l}\text { Days to } \\
\text { controlf }\end{array}$ & $\begin{array}{l}\text { Gestation at delivery } \\
\text { (weeks) }\end{array}$ & Outcome \\
\hline & & & & Control achieved & & & \\
\hline 3 & Tachycardia & 32 & Atrial flutter & Digoxin & 10 & 38 & Induced onset of labour; alive and well \\
\hline 9 & Tachycardia & 33 & $\begin{array}{l}\text { Supraventricular tachycardia/ } \\
\text { atrial flutter }\end{array}$ & Digoxin + verapamil & 11 & 40 & Induced onset of labour; alive and well \\
\hline 10 & $\begin{array}{l}\text { Intermittent } \\
\text { tachycardia }\end{array}$ & 34 & $\begin{array}{l}\text { Supraventricular tachycardia/ } \\
\text { atrial flutter }\end{array}$ & Digoxin + verapamil & 28 & 38 & Induced onset of labour; alive and well \\
\hline 13 & Tachycardia & 36 & Atrial flutter & Digoxin & 8 & 38 & Induced onset of labour; alive and well \\
\hline 14 & Tachycardia & 35 & Supraventricular tachycardia & Digoxin & 10 & 39 & Spontaneous onset of labour; alive and well \\
\hline 17 & Tachycardia & 32 & Supraventricular tachycardia & Digoxin & 16 & 40 & Spontaneous onset of labour; alive and well \\
\hline 20 & Tachycardia & 37 & Supraventricular tachycardia & Digoxin & 7 & 40 & Spontaneous onset of labour; alive and well \\
\hline 4 & $\begin{array}{l}\text { Intermittent } \\
\text { tachycardia }\end{array}$ & 30 & Supraventricular tachycardia & $\begin{array}{l}\text { Partial control } \\
\text { Digoxin + verapamil }\end{array}$ & - & 38 & $\begin{array}{l}\text { Spontaneous onset of labour; difficult to } \\
\text { control postnatally }\end{array}$ \\
\hline 2 & Tachycardia & 38 & Supraventricular tachycardia & $\begin{array}{l}\text { No control achieved } \\
\text { Digoxin }\end{array}$ & - & 38 & $\begin{array}{l}\text { Spontaneous onset of labour; prolonged } \\
\text { antiarrhythmic treatment }\end{array}$ \\
\hline 8 & Tachycardia & 35 & Supraventricular tachycardia & Digoxin & - & 38 & $\begin{array}{l}\text { Defaulted antenatal care; required direct } \\
\text { current conversion and antiarrhythmics }\end{array}$ \\
\hline 1 & Tachycardia & 32 & Atrial flutter & Control not attempted & - & 32 & $\begin{array}{l}\text { Induced onset of labour; respiratory distress } \\
\text { syndrome; necrotising enterocolitis, left } \\
\text { hemicolectomy }\end{array}$ \\
\hline
\end{tabular}

*Cases numbered in chronological order in which they presented.

tOverall mean 34.0 weeks.

fOverall mean ("control achieved" only) 12.9 days.

TABLE II-Clinical details of hydropic cases

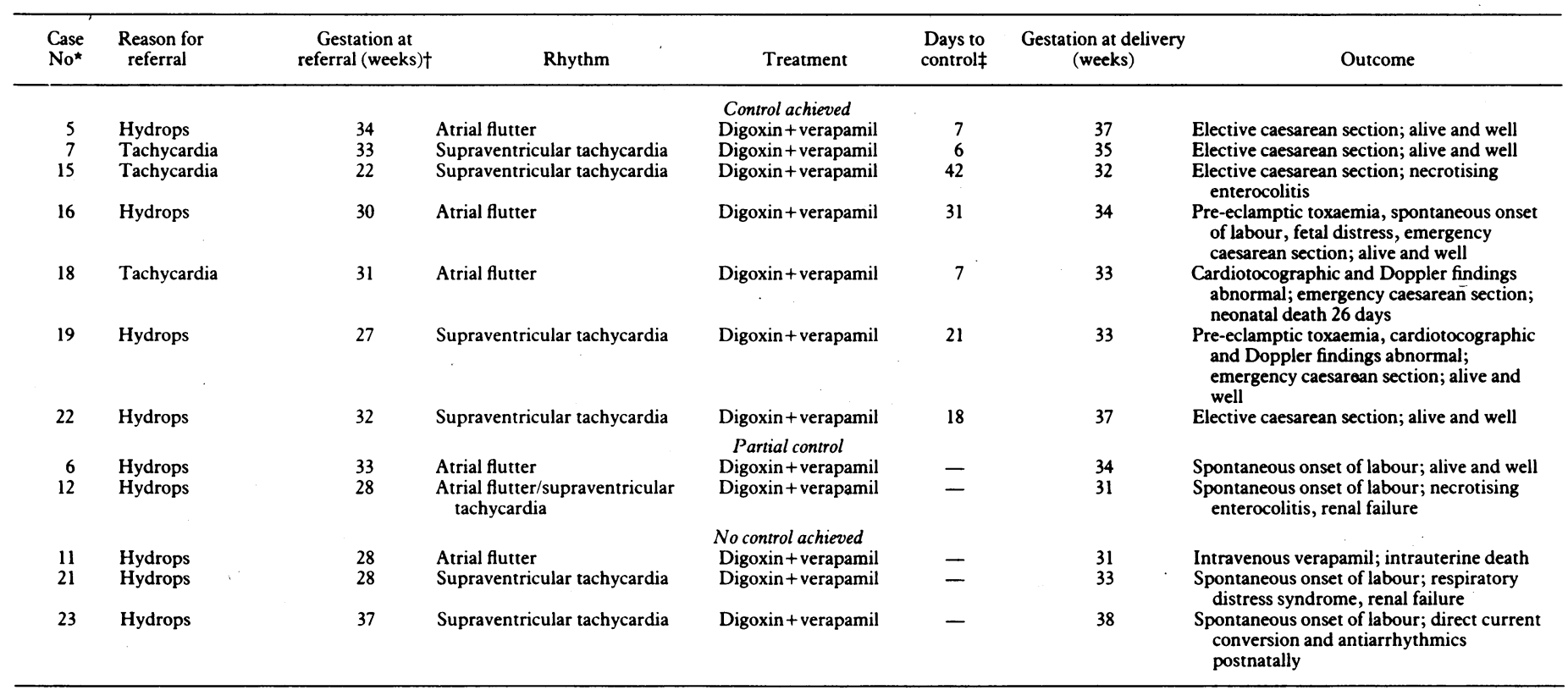

*Cases numbered in chronological order in which they presented.

fOverall mean 30.3 weeks.

†Overall mean ("control achieved" only) 18.8 days.

and table II the clinical details and outcome of treatment of those that were in heart failure. In all cases the fetal heart rate was 240 beats/min or over. No fetus was found to have structural heart disease. Convincing hydramnios was a feature occurring in one of the 11 non-hydropic pregnancies and 10 of the 12 with fetal hydrops. There was no difference between the groups in the fetal heart rate or types of disturbed rhythm present.

In the non-hydropic group case 1 (the first in the series) was delivered electively without treatment. This neonate suffered severe complications of prematurity, and all subsequent cases were therefore treated prenatally. All treated patients in this group were delivered after 37 weeks of gestation. None of those in whom rhythm control was achieved required neonatal treatment other than a maintenance dose of digoxin in the first year of life. In the two cases in which - successful conversion was not obtained one mother went into labour spontaneously within 24 hours of beginning treatment and the other defaulted from further antenatal care shortly after treatment was begun. Postnatal control of the tachyarrhythmias was more difficult when control had not been achieved in utero.

One of the hydropic fetuses (case 7) was in sinus rhythm when first seen by us but a reliable history of tachycardia had been obtained at the referring hospital. After admission the tachycardia was recorded echocardiographically. This fetus continued to have intermittent fetal tachycardia. Hydrops developed in one fetus, and in two others progression of hydrops from mild to moderate occurred in the time it took to gain control of the arrhythmia. In two cases a decrease in the severity of hydrops was seen after successful treatment.

Of the seven hydropic fetuses in which rhythm control was obtained, five had uncomplicated neonatal courses. Of the others, one (case 15) was delivered electively at 32 weeks in another centre against our advice. In case 18 , an emergency caesarean section was performed five days after cardiotocography and blood flow studies had shown reduced fetal movements and evidence of fetal compromise. In three of the five cases 
in which complete rhythm control was not obtained the mother went into spontaneous labour within the first week of treatment. In case 11 maternal treatment had not been successful by 12 days and a 20 gauge needle was therefore inserted into the umbilical vein at its placental insertion under ultrasound guidance and verapamil given directly to the fetus. This resulted in fetal asystole which could not be reversed.

Neither conversion to sinus rhythm nor eventual outcome appeared to be influenced by the initial rhythm disturbance. Table III summarises the relation between rhythm control and the types of arrhythmia in the two groups.

Maternal symptoms of digoxin toxicity necessitating adjustment of the dose were common when serum concentrations rose above $3.3 \mathrm{nmol} / \mathrm{l}$. There were no other maternal complications of antiarrhythmic treatment.

TABLE III-Results of treatment compared with types of rhythm in presence or absence of cardiac failure

\begin{tabular}{|c|c|c|c|}
\hline \multirow[b]{2}{*}{ Results of treatment } & \multicolumn{3}{|c|}{ Type of rhythm disturbance } \\
\hline & Atrial flutter & $\begin{array}{l}\text { Atrial flutter/ } \\
\text { supraventricular } \\
\text { tachycardia }\end{array}$ & $\begin{array}{l}\text { Supraventricular } \\
\text { tachycardia }\end{array}$ \\
\hline \multicolumn{4}{|c|}{ Non-hydropic cases } \\
\hline Control achieved & 2 & 2 & 3 \\
\hline Partial control & - & - & 1 \\
\hline No control & - & - & 2 \\
\hline No treatment & 1 & - & - \\
\hline Total & 3 & 2 & 6 \\
\hline \multicolumn{4}{|c|}{ Hydropic cases } \\
\hline Control achieved & 3 & - & 4 \\
\hline Partial control & 1 & 1 & - \\
\hline No control & 1 & - & 2 \\
\hline Total & 5 & 1 & 6 \\
\hline
\end{tabular}

\section{Discussion}

In over half of our patients the fetal tachycardia had been diagnosed before referral. Nine cases, however, were referred for investigation of non-immune fetal hydrops, and in these the causative tachycardia had not been noted by the referring hospital. In addition, hydrops had been known to be present in some of these cases for up to four weeks before referral. We emphasise the need to consider fetal tachycardia as a cause of nonimmune hydrops and to refer these cases promptly. The slightly earlier gestation at presentation of the hydropic fetuses was thought to be due to the commonly associated hydramnios having aroused clinical suspicion, leading to ultrasound evaluation and the detection of fetal hydrops.

Before maternal treatment is started the type of arrhythmia must be identified. In particular, ventricular tachycardia must be excluded, as this has been recorded prenatally ${ }^{10}$ and contraindicates treatment with digoxin and verapamil. The nature of the tachycardia is elucidated by timing of mechanical atrial and ventricular systole on the $M$ mode echocardiogram. In this way atrial flutter and most ventricular tachycardias can be differentiated from other supraventricular tachycardias. ${ }^{3}$

Our series shows some of the difficulties in assessing attempts at prenatal treatment. The absence of a control group in which tachycardias were not treated hinders analysis and the conclusions drawn. Accurate information on the natural course of all forms of arrythmia in utero is lacking. Nevertheless, before prenatal treatment was attempted atrial tachycardias were associated with hydrops, intrauterine death, and prematurity. ${ }^{12}$ Our rationale for treating all cases of atrial tachycardia diagnosed prenatally is to prevent or reverse cardiac failure. The inevitable progression of all cases from non-hydropic to hydropic is not proved. Nevertheless, progression did occur in three cases in this series. The possibility that the presence or absence of cardiac failure prenatally depends on the type of arrhythmia and the heart rate is not supported by our data, as we found no difference between the hydropic and non-hydropic groups in either of these features. A factor which may be important is the duration of the arrhythmia and its intermittent nature. Three fetuses were in sinus rhythm at the initial examination after referral for fetal hydrops. All were found to have a tachycardia at a later examination. Two are not included in this series, as they were sent back to the referring hospital before the diagnosis of intermittent tachycardia was made and were therefore not treated by us. The possibility of an intermittent tachycardia as a cause of fetal hydrops must be considered and the mother admitted for fetal heart rate monitoring. Doppler cardiotocography is unreliable and misleading for this and we have used phonocardiography ${ }^{13}$ for prolonged (12-24 hour) recording.

Based on experience we treat all hydropic fetuses with the mothers as inpatients. Non-hydropic fetuses may be treated in the outpatient department and delivered safely in local centres once conversion has been achieved. We chose digoxin as the most practicable treatment because of its known safety in pregnancy. Verapamil was added in refractory cases for its additive effect with digoxin. There appeared to be no maternal or fetal morbidity attributable to treatment. We achieved conversion to sinus rhythm in 14 of 22 patients overall, and in a further three partial control was achieved. These results are comparable with other series. ${ }^{811}$ In three of five cases in which control was not achieved delivery took place less than a week after the start of antiarrhythmic drugs, before adequate treatment could be given. A further case in this group was not treated fully according to our regimen because of poor maternal compliance.

Sequential maternal serum drug concentrations during treatment coupled with cord blood sampling has allowed us to begin to understand placental transfer of these drugs. Many workers have reported failure of digoxin and verapamil and have tried various other drugs, such as procainamide, quinidine, and amiodarone. ${ }^{6.8} \mathrm{We}$, however, find that high doses given for two to three weeks are necessary to achieve rhythm control, particularly in hydropic fetuses. Our results of fetal blood sampling from the umbilical cord under ultrasound control and of cord blood sampling at delivery compared with simultaneous maternal sampling indicate that placental transfer of digoxin is around $40 \%$ and of verapamil of the order of $10-20 \%$.

With the exception of the one case which progressed from the non-hydropic to the hydropic group, analysis of the outcome in the non-hydropic group does not show a clear advantage to the fetus of successful treatment. All 11 cases were delivered at term irrespective of rhythm control in utero. In all three cases in which complete control had not been achieved prenatally, however, difficulty was experienced in gaining control postnatally.

All the patients in the hydropic group required both digoxin and verapamil and, on average, a longer duration of treatment to achieve conversion. In this group where control was achieved reversal of the ascites took many days or even weeks after return to sinus rhythm. Mortality and morbidity occurred whether control, partial control, or no control was achieved. It appears that prolongation of gestation occurred after successful treatment. The absence of a control group of untreated cases does not allow us to conclude that treatment caused this delay in delivery. Nevertheless, our results suggest that premature delivery, whether spontaneous or induced, should be 
avoided. Our one experience with direct fetal treatment was not successful, and possibly a longer duration of transplacental treatment would have been more appropriate.

In our series the Wolff-Parkinson-White syndrome as the underlying cause of the tachycardia was found in three of the 22 infants who had a postnatal electrocardiogram.

In summary $\mathrm{p}_{\boldsymbol{c}}$,hological atrial tachycardias are a potential cause of non-immune hydrops. As these rhythm disturbances may be intermittent, this diagnosis should be considered in all cases of fetal hydrops even if the tachycardia is not present at the initial examination. It is not possible to predict which of the non-hydropic fetuses will progress to become hydropic. We therefore believe that an attempt at transplacental treatment is valid in all cases. Our results show that maternal transplacental treatment is both safe and effective and may avert preterm delivery and its attendant morbidity.

DJM was on secondment from University College Hospital. LDA and DCC were supported by the British Heart Foundation and MJT by the British Heart Foundation and the Joseph Levy Foundation.
1 Siber DL, Durnin RE. Intrauterine atrial tachycardia. Am f Dis Child 1969;117:722-6.

2 Hedvall G. Congenital paroxysmal tachycardia-a report of three cases. Acta Paediatr Scand 1973;62:550-2.

3 Allan LD, Anderson RH, Sullivan ID, Campbell S, Holt DW, Tynan M Evaluation of fetal arrhythmias by echocardiography. Br Hearl $\mathcal{F} 1983 ; 50$ Evalua

4 Kleinman CS, Donnerstein RL, Jaffe CC, et al. Fetal echocardiography. A tool for the evaluation of in utero cardiac arrhythmias and the monitoring of in utero therapy: analysis of 71 patients. Am $\mathcal{F}$ Cardiol 1983;51:237-43.

5 Silverman NH, Enderlein MA, Stanger P, Teitel DF, Heymann MA, Golbus MS. Recognition of fetal arrhythmias by echocardiography. Journal of Clinical Ultrasound 1985;13:255-63.

6 Dumesic AD, Silverman NH, Tobias S, Golbus MS. Transplacental cardioversion of fetal supraventricular tachycardia with procainamide. $N$ Engl $\mathcal{F}$ Med 1982;37:1128-31.

7 Spinnato JA, Shaver DC, Flinn GS, Sibai BM, Watson DL, Martin-Carcia J. Fetal supraventricular tachycardia: in utero therapy with digoxin and Fetal supraventricular tachycardia: in utero therapy with
quinidine. foumal of Obstetrics and Gynecology 1984;64:730-5.

8 Wladimiroff JW, Stewart PA. Treatment of fetal cardiac arrhythmias. $\mathrm{Br}$ J Hosp Med 1985;9: 134-40.

9 Allan LD, Crawford DC, Anderson RH, Tynan M. Echocardiographic and anatomical correlates in fetal congenital heart disease. Br Heart $\mathrm{f}$ 1984;52: $542-8$

10 Shenker L. Fetal cardiac arrhythmias. Obstet Gynecol Surv 1979;34:8, 561-72. 1 Kleinman CS, Copel JA, Weinstein EM, Santulli TV, Hobbins JC. Treatment of fetal supraventricular tachyarrhythmias. Journal of Clinical Ultrasound 1985;13:265-73.

12 Schreiner RL, Hurwitz RA, Rosenfeld CR, et al. Atrial tachyarrhythmias associated with massive edema in the newborn. $\mathcal{F}$ Perinat Med 1978;6:274-8.

13 Colley N, Talbert DG, Southall DC. Fetal phonocardiography. Biophysical profile in the fetus from a phonographic sensor. Eur 7 Obstet Gynecol Reprod Biol 1986;23:261-6.

(Accepted 2 March 1988)
University Department of Clinical Oncology, Newcastle General Hospital, Newcastle upon Tyne NE46BE

James Carmichael, MD, lecturer Brian M J Cantwell, MD, senior lecturer

Cathryn M Edwards, MA, medical student

Adrian L Harris, DPHIL, professor

Beecham Pharmaceuticals Research Division, Harlow, Essex

W Garth Rapeport, MRCP, clinical pharmacologist

Correspondence to: Professor Harris.

\section{The serotonin type 3 receptor antagonist BRL 43694 and nausea and vomiting induced by cisplatin}

\author{
James Carmichael, Brian M J Cantwell, \\ Cathryn M Edwards, W Garth Rapeport, \\ Adrian L Harris
}

In most patients receiving cisplatin nausea and vomiting are observed one to six hours after the drug is given and last for up to 10 days $^{1}$; currently available antiemetics show limited efficacy. At conventional doses metoclopramide is inactive, but at high doses it is effective against the vomiting induced by cisplatin, although extrapyramidal reactions are observed. ${ }^{2}$ At these doses metoclopramide competitively blocks serotonin type 3 receptors. ${ }^{3}$ Selective serotonin type 3 receptor antagonists exhibit potent antiemetic activity in ferrets and recently GR $38032 \mathrm{~F}$ was shown to be effective in patients receiving mildly emetic drugs, none of whom received cisplatin. ${ }^{4}$ We report the efficacy and tolerance of the new serotonin type 3 receptor antagonist BRL $43694^{5}$ in patients receiving cisplatin.

\section{Patients, methods, and results}

Cisplatin was given intravenously over 30 minutes, followed by BRL 43694 given by intravenous infusion in $250 \mathrm{ml} 0.9 \%$ saline over 30 minutes. The first five patients received concurrent dexamethasone $4 \mathrm{mg}$ four times a day, but as the infusions of BRL 43694 were noticeably effective BRL 43694 was subsequently infused on its own. After finishing treatment patients were hydrated for 24 hours. The number of episodes of vomiting and dry retching were recorded before the infusion and at one, four, six, eight, and 24 hours after it. In addition, severity of nausea was subjectively assessed with both global four point severity scores (before the infusion and at four and 24 hours after it) and $10 \mathrm{~cm}$ visual analogue scores (before the infusion and at one, four, and six hours after it), which were analysed with a paired Wilcoxon signed rank test.

Eighteen male and four female patients were studied (mean age $47 \cdot 4$ (SD 13) years), 13 of whom had

Details of treatment of 22 patients receiving BRL 43694 as antiemetic for control of nausea and vomiting induced by cisplatin

\begin{tabular}{|c|c|c|c|c|c|c|c|}
\hline \multirow{2}{*}{$\begin{array}{l}\text { Case } \\
\text { No }\end{array}$} & \multirow{2}{*}{$\begin{array}{c}\text { BRL } \\
43694 \\
(\mu \mathrm{g} / \mathrm{kg})\end{array}$} & \multirow{2}{*}{$\begin{array}{c}\text { Cisplatin } \\
\left(\mathrm{mg} / \mathrm{m}^{2}\right)\end{array}$} & \multirow[b]{2}{*}{ Other cytotoxics given } & \multicolumn{2}{|r|}{ Nausea } & \multirow{2}{*}{$\begin{array}{c}\text { No of } \\
\text { vomiting } \\
\text { episodes }\end{array}$} & \multirow{2}{*}{$\begin{array}{l}\text { Other } \\
\text { antiemetics } \\
\text { given }\end{array}$} \\
\hline & & & & Grade & Time of onset $(\mathrm{h})$ & & \\
\hline 1 & 10 & 50 & Bleomycin, methotrexate & 3 & 12 & 7 & Yes \\
\hline 2 & 10 & 50 & None & 4 & 4 & 6 & Yes \\
\hline $3^{\star}$ & 20 & 50 & Ifosfamide & 3 & 12 & None & Yes \\
\hline 4 & 20 & 50 & Doxorubicin & & None & None & No \\
\hline $5^{\star}$ & 20 & 60 & Hydroxyurea, bleomycin & & None & None & No \\
\hline $6^{\star}$ & 30 & 20 & Etoposide & & None & None & No \\
\hline 7 & 30 & 50 & Mitomycin & 2 & 12 & 3 & No \\
\hline $8^{\star}$ & 30 & 75 & None & & None & 5 & No \\
\hline $9 \star$ & 40 & 40 & Doxorubicin, hydroxyurea, bleomycin & & None & None & No \\
\hline $10^{\star}$ & 40 & 40 & Ifosfamide, vincristine & & None & None & No \\
\hline 11 & 40 & 50 & None & 2 & 6 & 1 & Yes \\
\hline $12^{\star}$ & 40 & 50 & None & 2 & 6 & 2 & Yes \\
\hline $13^{\star}$ & 40 & 60 & Doxorubicin, hydroxyurea, bleomycin & 3 & 12 & 5 & Yes \\
\hline $14^{\star}$ & 40 & 60 & Doxorubicin, hydroxyurea, bleomycin & & None & None & No \\
\hline 15 & 40 & 75 & None & 2 & 18 & 3 & Yes \\
\hline $16^{\star}$ & 40 & 75 & None & 4 & 4 & 2 & Yes \\
\hline 17 & 40 & 75 & None & & None & None & No \\
\hline $18^{\star}$ & 40 & 75 & None & & None & None & No \\
\hline $19^{\star}$ & 40 & 75 & Mitozantrone & & None & None & No \\
\hline $20^{\circ}$ & 40 & 75 & None & & None & None & No \\
\hline $21^{\star}$ & 40 & 75 & None & & None & None & No \\
\hline 22 & 40 & 100 & Fluorouracil & 2 & 16 & 2 & Yes \\
\hline
\end{tabular}

^Patient had previous chemotherapy. 